\title{
Degree of fragmentations and number of distinctive features in the recognition of pictured objects by children and adults
}

\author{
FRANK S. MURRAY and ELIZABETH L. KINNISON \\ Randolph-Macon Woman's College, Lynchburg, Virginia
}

\begin{abstract}
Fragments $(20 \%, 35 \%$, and $50 \%)$ of pictures of line drawings of common objects, showing $20 \%$, $40 \%, 60 \%$, or $80 \%$ of the distinctive features, were presented to 44 nursery school children and 44 female undergraduates. Results indicated that the total number and the percentage of distinctive fragments played a significant part in the recognition of pictures: distinctive features were most effective when the representations were most impoverished. A trend was obtained between the percentage of distinctive fragments and the total number of fragments. College students needed fewer and less distinctive fragments for recognition than did nursery school children. Results were interpreted using the concepts of abstraction and filtering of distinctive features as proposed by Gibson (1969).
\end{abstract}

The recognition of objects in pictures is a difficult perceptual skill for children because pictures lack information provided by the real objects. As the fidelity of the representation decreases, greater perceptual skills are required to recognize the object. One technique that is used to study the perception of impoverished representations of objects is incomplete pictures (Gollin, 1960, 1961, 1962, 1966; Leeper, 1935; Mooney, 1957; Murray \& Szymczyk, 1978; Street, 1931). The studies of Gollin (1961) and Murray and Szymcyk (1978) are most relevant to the present paper and are briefly described.

Gollin (1961) used 11-20 line drawings of common objects of varying fragmentations as stimuli for several experiments. Each of the objects was represented by a series of five drawings that ranged from a most incomplete to a complete representation. He found a significant relationship between chronological age and the amount of representation required for recognition of the pictured objects. Adults recognized objects at a greater degree of fragmentation than did children. When training was given to subjects on the complete or the intermediately fragmented representations of the objects, training with the fragmented representations was far more successful than training with the complete representations. However, even with training, only a mean of 7.5 out of the 20 most incomplete representations were identified by adults, and only an average of 1 out of 20 were identified by young children.

Murray and Szymczyk (1978) varied the distinctive features of incomplete pictures and found a difference in recognition when $75 \%$ versus $25 \%$ of the distinctive fea-

Portions of this paper were presented at the 58th annual meeting of the Eastern Psychological Association, Arlington, VA, April 10, 1987. Requests for reprints should be sent to Frank S. Murray, Psychology Department, Randolph-Macon Woman's College, Lynchburg, VA 24503. tures were present; these differences were statistically significant for both children and adults. They also showed that the degree of fragmentation was not a factor since the same number of fragments were present for the two types of representations. Murray and Szymczyk's results supported Gibson's (1969) contention that neither the degree of fragmentation nor the redundant information in the pictures is the crucial factor in pictorial recognition. However, Murray and Szymczyk used only two degrees of fragmentation and two degrees of distinctive features.

The purpose of the present research was to test the importance of the degree of fragmentation versus the number of distinctive features. The present study was similar to Murray and Szymczyk's (1978) study, but included three degrees of fragmentation and four degrees of distinctive features for each pictorial representation. In this way, a more detailed analysis of the effects of fragmentations and distinctive features on perceptual recognition by children and adults could be obtained.

\section{METHOD}

\section{Subjects}

A total of 88 subjects participated in this study; 44 of the subjects were from the First Presbyterian Church Nursery School, Lynchburg, Virginia, and the other 44 subjects were undergraduate female volunteers from Randolph-Macon Woman's College. The mean age of the nursery school children was 4 years, 2 months, and of the college students, 20 years, 10 months.

\section{Stimuli}

Slides were made of 12 line drawings of common objects: airplane, car, dog, scissors, squirrel, hammer, table, telephone, fish, tricycle, elephant, and boot. The elephant and boot were used for familiarizing the subjects with the task. Each of the pictorial objects was divided into $1-\mathrm{cm}$ fragments, and $20 \%, 35 \%$, or $50 \%$ of the total fragments were present. In addition, $20 \%, 40 \%, 60 \%$, or $80 \%$ of these lines represented the distinctive features of each object. The criteria for distinctive and 
nondistinctive features were made in a previous study by having $10 \mathrm{stu}-$ dents of Randolph-Macon's Woman's College list the three most defining, distinctive, or salient features of each object. A consensus list was completed by rank order; for example, the most distinctive features of an airplane ranked by 9 of 10 students were the wings, propeller, and vertical stabilizer (Murray \& Szymczyk, 1978).

To illustrate the procedure for constructing the stimuli, the airplane is used as an example. This line drawing was composed of 144 fragments. Of the 144 fragments, 68 were considered distinctive and 76 nondistinctive. For the condition in which only $20 \%$ of the total fragments were present, the airplane contained 29 fragments. When $20 \%$ of the distinctive features were present, 6 of the 29 were distinctive (.20 of 29) and 23 nondistinctive. With $40 \%$ distinctive features, 12 of the 29 fragments were distinctive and 17 nondistinctive. For the $60 \%$ and $80 \%$ distinctive features of the airplane, 17 and 23 of the distinctive features were included for these respective conditions. A similar procedure was used for the conditions in which $35 \%$ and $50 \%$ of the total fragments were present. See Figure 1 for examples of the airplane used in this experiment. For each picture, fragments were numbered and selected by consulting a table of random numbers.

\section{Apparatus}

Each slide was projected using a Kodak Carousel slide projector, Model $650 \mathrm{H}(300-\mathrm{W}$ bulb). The projected image was $35 \times 21 \mathrm{~cm}$, and the subjects sat $70 \mathrm{~cm}$ away from the projection screen.

\section{Procedure}

The experimenter (E.K.) was introduced to the children by their teachers, who explained to the children that the experimenter was going to show them some pictures, and that they were to guess what objects were in the pictures. The adults were told that they would be participating in an experiment on perception. All subjects were given a familiarization task. For each child, a complete picture of a boot was projected on the screen, and the child was asked to identify it. Then the child was shown an incomplete representation of the boot containing $75 \%$ of the fragments. The child was told that this picture did not have all its lines, and was asked to identify it. After this, the child was shown less completed representations (50\% and $25 \%$ ) of the boot, and again asked to identify it. The child was corrected for incorrect responses and shown again the complete representation of the boot. The child was then told that the next pictures he/she was going to see would have the fewest lines presented first. A slide of an elephant containing $25 \%$ of the completed picture was projected on the screen. Then $50 \%$ and $75 \%$ representations of the completed elephant picture were shown. The child was asked to identify the object in the pictures, and was corrected if incorrect in his/her response. Finally, to determine whether the child completely understood the task, $50 \%$ representations of the boot and the elephant were presented. All the children successfully identified both. The adults were informed that their task was to identify fragmented pictures, and were shown the same slides as the children.

Each subject in the two groups, nursery school children and college students, was assigned randomly $(n=11)$ to one of the four distinctive features conditions. Each subject was presented with the most incomplete picture (20\%) first, and asked to identify the object, and then the two less incomplete patterns (35\% and $50 \%$ ). Each slide was presented for $5 \mathrm{sec}$. Every subject was shown 30 slides $(10$ objects with 3 slides for each). All subjects were tested individually, and each session lasted 8-10 min.

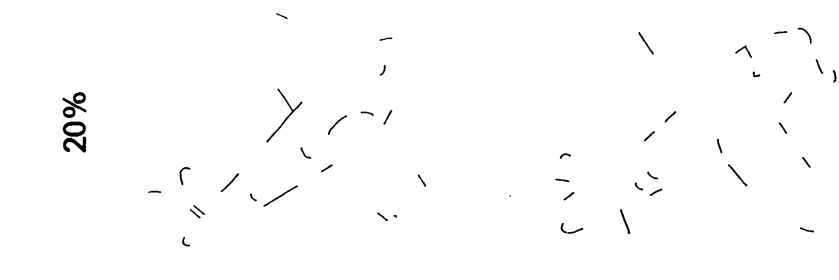

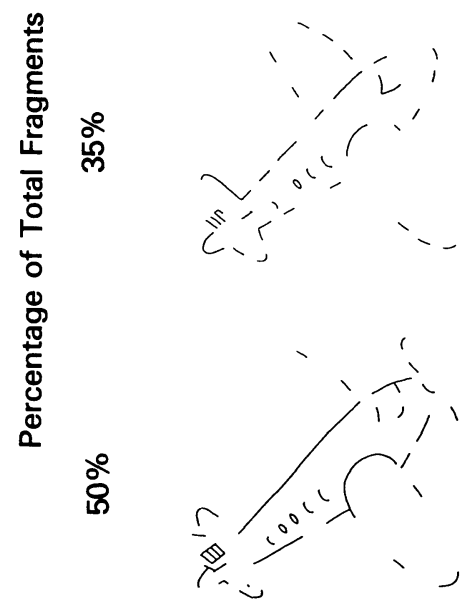

$20 \%$
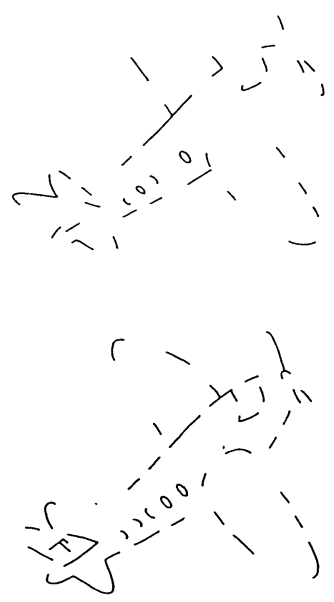

$40 \%$
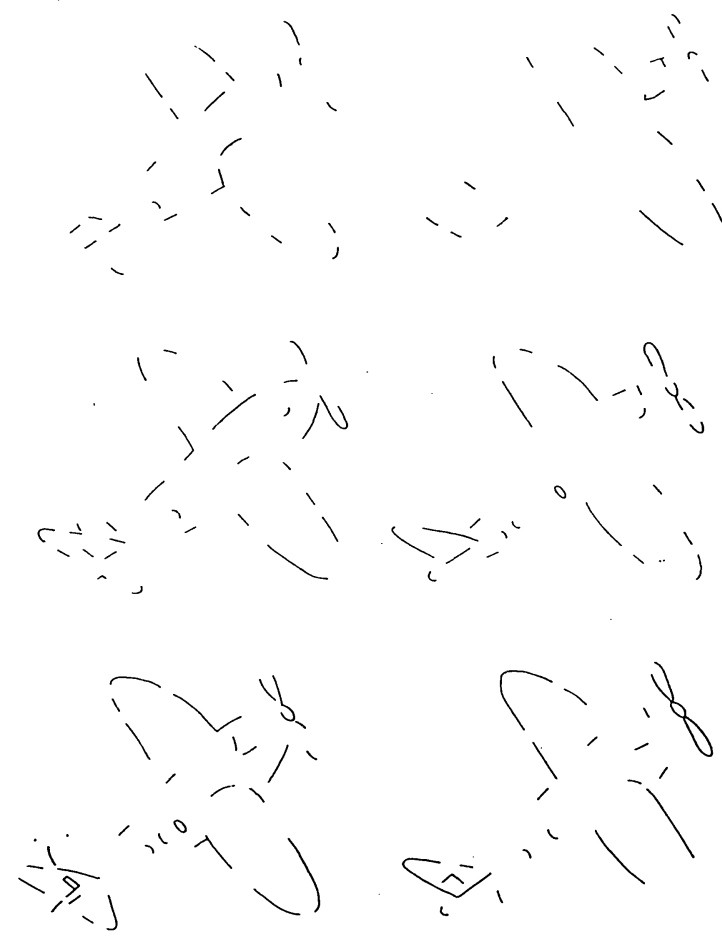

$60 \%$

Percentage of Distinctive Features

Figure 1. An example of the various pictorial representations used in this experiment. The distinctive features of the airplane are the wings, the propeller, and the vertical stabilizer. Subjects were assigned randomly to the four distinctive features conditions, and within each condition, each subject was exposed to a $20 \%$, a $35 \%$, and a $50 \%$ representation of the total fragments of each picture. 


\section{RESULTS AND DISCUSSION}

The results of the present experiment indicate (1) that recognition of incomplete pictures was facilitated if distinctive features were present, (2) that recognition was related to the number of fragments, and (3) that adults recognized more pictures than did children. Inspection of
Figure 2 clearly shows that the percentage of distinctive features plays an important role in the recognition of very impoverished (20\%) representations, and that young children require more of the fragments than do adults.

These data were analyzed using a $2 \times 4 \times 3$ (groups $X$ distinctive features $\times$ number of fragments) mixed analysis of variance. The nursery school children identi-
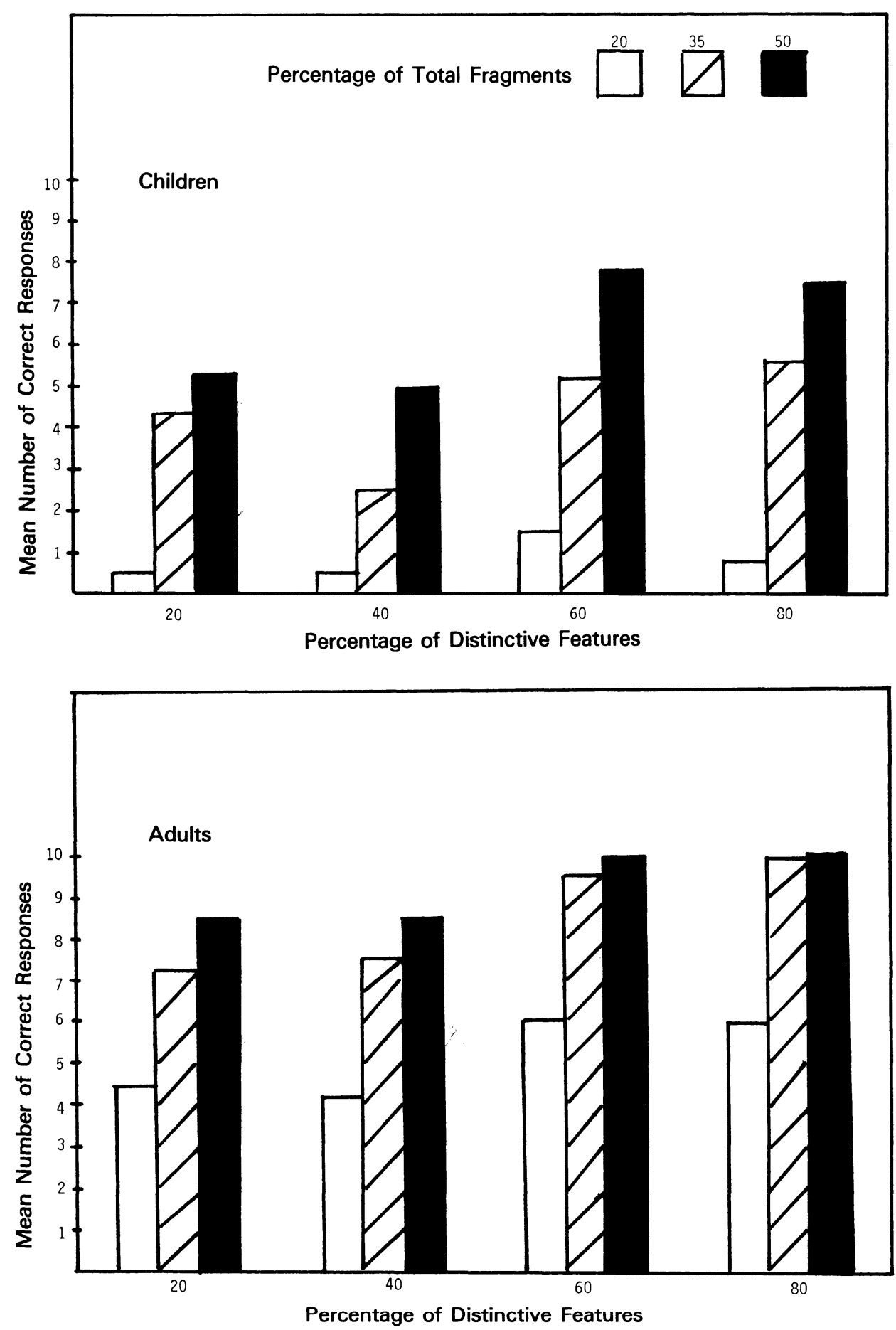

Figure 2. Mean number of correct responses for children and adults to the 10 pictures and to the percentage of distinctive features and of total fragments. The maximum mean score obtainable is 10. 
fied a mean of 11.6 slides out of 30 , and the college students a mean of 23.0 slides $[F(1,80)=287.8, p<.01]$. This analysis also revealed a significant effect of distinctive features $[F(3,80)=19.2, p<.05]$, effect of total fragments $[F(2,160)=503.5, p<.01]$, and interaction between the three factors (all significant at $p<.05$ ).

The results of this study extend and support previous results reported in this area (Gollin, 1960, 1961, 1962; Murray \& Szymczyk, 1978). These studies also reported differences in recognitions of incomplete pictures between children and adults. As in Murray and Szymczyk's study, distinctive features played an important part in the recognition of fragmented pictures. In addition, the present study showed that the number of fragments contained in a picture was also an important factor in recognition; the fewer the fragments, the more errors in recognition. This was a greater problem for the nursery school children than for the college students.

The findings of this study lend support to Gibson's (1969) contention that as long as incomplete pictures retain the distinctive features of objects, success in recognition should follow. According to Gibson, differentiation of stimuli in the environment is achieved by the detection of the distinctive features and the invariant relations of the stimuli. Through a process she calls abstraction, the distinctive and invariant properties of stimuli are discovered. Another process that she terms filtering is as basic to perceptual differentiation as is abstraction. Filtering is the ability to ignore the irrelevant features of stimuli. Adults perform better than children on perceptual tasks, Gibson contends, because perceptual development is characterized by a progressive increase in the specificity of discrimination of stimuli in the environment. Accordingly, adults are more precise in their responses to finer differences in stimuli and are more active and systematic in their search for the distinctive features of stimuli than are children.

Another important aspect of the present study was the quantification of the fragmented pictures used. In this way, a clearer measure of the effects of distinctive and nondistinctive features could be obtained. Finally, the incomplete pictures developed for the present study could be used in the assessment of visual impairment of neurological cortical lesions, since more precise information could be obtained from the responses to the features of these pictures than those previously used in diagnosing visual impairments (Warrington \& James, 1967; Warrington \& Taylor, 1973).

\section{REFERENCES}

Gibson, E. J. (1969). Principles of perceptual learning and development. New York: Appleton-Century-Crofts.

Gollin, E. S. (1960). Developmental studies of visual recognition of incomplete objects. Perceptual \& Motor Skills, 11, 289-298.

Gollin, E. S. (1961). Further studies of visual recognition of incomplete objects. Perceptual \& Motor Skills, 13, 307-314.

Gollin, E. S. (1962). Factors affecting the visual recognition of incomplete objects: A comparative investigation of children and adults. Perceptual \& Motor Skills, 15, 583-590.

Gollin, E. S. (1966). Serial learning and perceptual recognition in children: Training, delay, and order effects. Perceptual \& Motor Skills, 23, 751-758.

LEEPER, R. A. (1935). A study of a neglected portion of the field of learning-The development of sensory organization. Journal of Genetic Psychology, 46, 44-75.

Mooney, C. M. (1957). Age in the development of closure ability in children. Canadian Journal of Psychology, 11, 219-226.

MurRay, F. S., \& SZYMCZYK, J. M. (1978). Effects of distinctive features on recognition of incomplete pictures. Developmental Psychology, 14, 356-362.

STREeT, R. F. (1931). A gestalt completion test. New York: Columbia University Press.

WARRINGTON, E. K., \& JAMES, M. (1967). An experimental investigation of facial recognition in patients with unilateral cerebral lesions. Cortex, 3, 317-326.

WARRINGTON, E. K., \& TAYLOR, A. M. (1973). The contribution of the right parietal lobe to object recognition. Cortex, 9, 152-164.

(Manuscript received September 10, 1988.) 